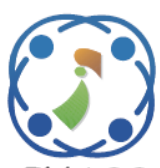

\title{
Differential Drive Analysis of Spherical Magnetic Robot Using Multi-Single Board Computer
}

\author{
Sethakarn Prongnuch ${ }^{1 *}$ \\ Suchada Sitjongsataporn ${ }^{2}$ \\ ${ }^{1}$ Department of Computer Engineering, Faculty of Industrial Technology, \\ Suan Sunandha Rajabhat University, Bangkok, Thailand \\ ${ }^{2}$ Department of Electronic Engineering, Mahanakorn Institute of Innovation (MII), \\ Faculty of Engineering and Technology, Mahanakorn University of Technology, Bangkok, Thailand \\ * Corresponding author's Email: sethakarn@ssru.ac.th
}

\begin{abstract}
This paper presents a spherical magnetic robot named 'CE-R1' propelled by an inner drive unit and a magnetic balancing unit rolling without slipping on a plane. A spherical magnetic robot 'CE-R1' consists of two parts as a domed head and a ball-shaped body with contactless and controlled via Bluetooth. A non-holonomic model and wheel-drive locomotion are interested in a spherical mobile robot. Sphere movement is controlled by a differential drive from the inner drive unit inside the sphere. Firstly, the magnetic interaction in a magnetic balancing unit is applied to the connection of a domed head and a ball-shaped body with contactless. Secondly, a differential drive of proposed spherical magnetic robot 'CE-R1' with an inner drive unit inside is derived and deployed with the multi-single computer board controller. Hardware of prototype 'CE-R1' is designed including the multi-single board computer for wireless charger, voice recognition system and controlling the 'CE-R1'. The explicit experiments of proposed ' $\mathrm{CE}-$ $\mathrm{R} 1$ ' spherical magnetic robot are tested as a faculty-assistive guide robot controlled through application at the faculty lobby area in the Suan Sunandha Rajabhat University. This work proposed here is a step towards the overall goal of an autonomous spherical mobile robot.
\end{abstract}

Keywords: Spherical magnetic robot, Differential drive, Magnetic balancing unit, Inner drive unit, Multi-single board computer.

\section{Introduction}

A spherical mobile robot with the internal drive unit can be distinguished from other robots by its ability to move autonomously. The most famous spherical mobile robot in this world is an astromechanic droid [1] named 'BB-8' that has appeared on Star Wars Episode VII-The Force Awakens [2]. Due to a ball shaped body and a domed head, low rolling resistance and mobility in any direction make a spherical mobile robot more appealing for a social robot with information-service function to assist human for public service [3].

As passionate about BB-8 for a PR robot, a spherical magnetic robot is introduced as a faculty guide robot for information service by taking the front desk of faculty to do a repetitive work. This leads to inspire the design of faculty-assistive robot controlled through a mobile application illustrated in Fig. 1. Multi-single board computer is the collaboration and co-operation of many single-boardcomputer with each own the microprocessor, memory, input/output and other features requirement of a functional computer operating as the embedded computer controller.

According to understanding the mobile robot system, firstly the fundamental of mechanics is to study as forces and displacements in order to know how the dynamics as the motion of mobile robot system in response to forces. The aim of proposed research is how to use the devices and equipment from the local market to innovate a robot empowered by digital system design, which is the difference of techniques from the spherical magnetic robots in the past. 
As stated in the previous research, the conventional robots are controlled by mechanics, while the concept design of proposed robot is based on the digital system design in order to support the innovation in the future.

In our research, we present the spherical magnetic robot named 'CE-R1' under different features as:

1) A magnetic balancing unit and an inner drive unit for robot movement controlling by user via application;

2) An interaction design for human-robot interaction, and

3) Specifications and features of prototype robot. The organization of the paper is as follows: Section 2 describes the background and related works about the spherical mobile robot. In Section 3, the magnetic balancing unit is explained briefly, and Section 4 proposes the inner drive unit of proposed 'CE-R1' spherical magnetic robot. In Section 5, an interaction design is described using the human-robot interaction. Section 6 specifies the prototype robot and Section 7 conducts the design and kinematics of prototype 'CER1' spherical magnetic robot. Tuning up the drive system and experimental results are reported in Section 8 and Section 9 provides concluding remarks.

\section{Background and related work}

There are many mobile robots expanding fields of scientific research [4]. Due to their abilities, the mobile robots can substitute humans in many applications as guide, personal service, assistant, and so on. Locomotion is a kind of basic robot movement by understanding the mechanism and kinematics, dynamics, and controller. Based on the robots movement, we can be classified as the holonomic and non-holonomic drive system.

Holonomic drive and non-holonomic drive [5] refer to the relationship between the controllable degree of freedom and total degrees of freedom of a robot. The controllable degree of freedom is specified. If the controllable degree of freedom of the robot is equal to total degrees of freedom, then the robot is called the holonomic drive. Similarly, if the controllable degree of freedom of the robot is less than total degrees of freedom, then the robot is called the non-holonomic drive.

The motion of ball-shaped robot has been interested in the drive system inside a spherical shell in the mechanics and dynamic. In particular, the spherical mobile robots have been propelled using various mechanisms installed inside a shell such as wheel carriages, pendulums, gyroscopes and outside a shell [6].

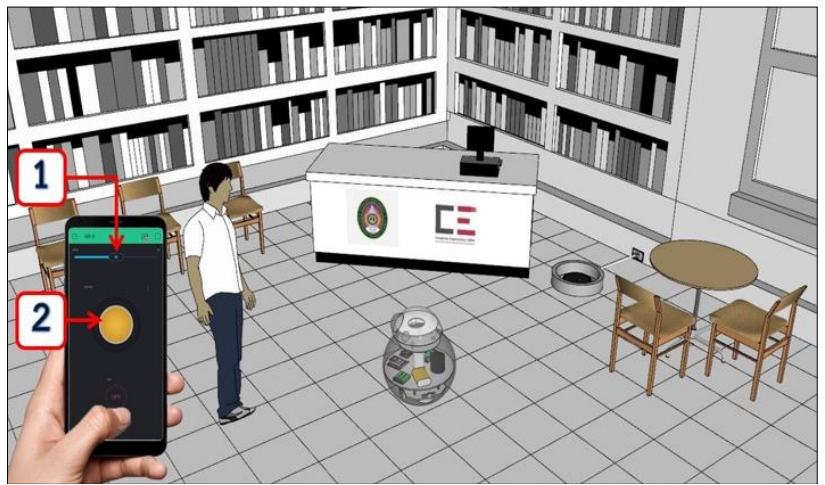

Figure. 1 A spherical magnetic robot designed for a faculty assistive PR robot

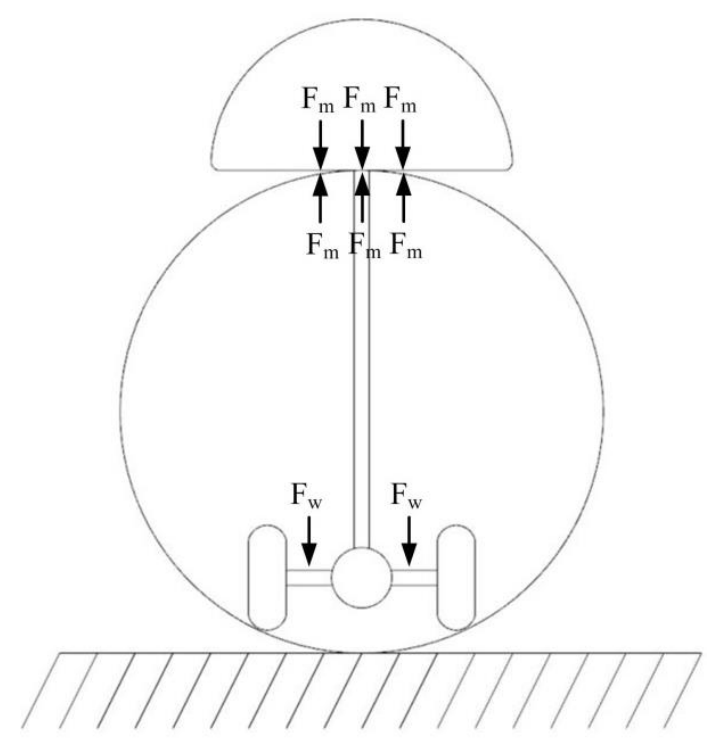

Figure. 2 Diagram illustrating the forces inside the spherical magnetic robot

Based on the holonomic kinematics, the spherical robot with an internal omniwheel platform [7] has been derived within the framework of a kinematic model and a dynamic model. Omniwheel is a wheel with small rollers carrying around which are perpendicular to the turning direction. The effect is that the omniwheel will also slide laterally with great ease.

Spherical robots based on the non-holonomic kinematics have been presented [8-14]. A structure of a spring-loaded design of the spherical mobile robot was illustrated in [11]. The motion analysis of spherical mobile robot [12] was derived while rolling on a plane. The proportional-derivative controller for the path following of spherical mobile robot [13] was investigated. Spherical robot with a control moment gyroscope group inside [14] has been studied in the motion control by simulation.

The conventional robots of the research survey and references are using the main concept design in the mechanics. There is no previous research created 
a spherical magnetic robot based on the digital system design with the devices from the local markets. This leads to start being an innovation in the future.

\section{Magnetic balancing unit}

In this section, we propose the magnetic balancing unit inspired by [15]. Magnetic balancing unit (MBU) is a controlled system that the head part of the spherical magnetic robot can connect with the spherical body part using the magnetic interaction.

In order to make a balance of the head part, the magnets are installed at the base of the head and at the top of the stand axis connected with the inner drive unit (IDU) inside the sphere as illustrated in Fig. 2. The magnetic force $F_{m}$ is a non-contact force that acts on the surface between the head and the sphere. The magnetic field happened in the space between two objects placed with the magnets can help the head part of moving freely on the sphere while rolling. According to balance on the floor while moving, the iron disc weight plate is designed to be statically stable. The force of weight plate $F_{w}$ is happening on the wheel-drive locomotion as shown in Fig. 2.

\section{Inner drive unit}

IDU is described on the differential drive in the form of the wheel-drive locomotion.

By simplifying assumption based on the nonholonomic constraint that each wheel of the spherical magnetic robot can roll without slipping [5, 16]. Kinematic model is described in the state space of transition equations as [5]

$$
\dot{\boldsymbol{q}}=\left[\begin{array}{c}
\dot{x} \\
\dot{\boldsymbol{y}} \\
\dot{\boldsymbol{\theta}}
\end{array}\right]=\left[\begin{array}{cc}
\cos \theta & 0 \\
\sin \theta & 0 \\
0 & 1
\end{array}\right] \cdot\left[\begin{array}{c}
v \\
\omega
\end{array}\right]
$$

where $v$ denotes the linear velocity between the wheel and ground and $\omega$ is the angular velocity of the robot that is equal to the angular velocity of wheels along the vertical axis.

By following the unicycle model [5], the differential drive of spherical magnetic robot is described a model followed the inputs from the speed of right wheel $v_{r}$ and of the left wheel $v_{l}$ as shown in Fig. 3 as

$$
\left[\begin{array}{c}
v \\
\omega
\end{array}\right]=\left[\begin{array}{cc}
r / 2 & r / 2 \\
r / L & -r / L
\end{array}\right] \cdot\left[\begin{array}{l}
v_{r} \\
v_{l}
\end{array}\right]
$$

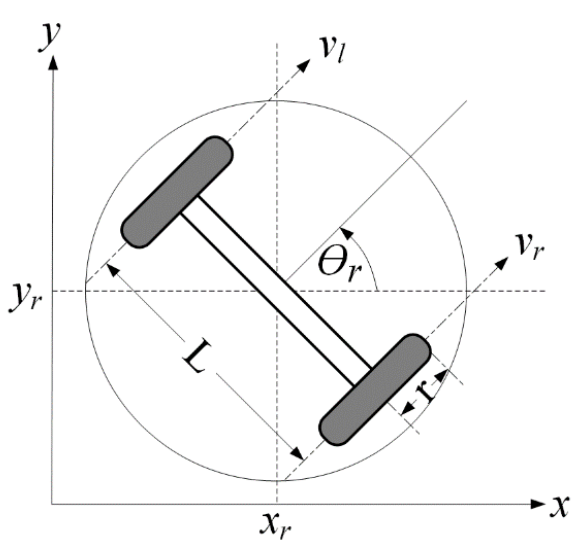

Figure. 3 Geometrical structure of differential drive, where $\mathbf{q}=\left[\mathbf{x}_{\mathbf{r}}, \mathbf{y}_{\mathbf{r}}, \boldsymbol{\theta}_{\mathbf{r}}\right]^{\mathbf{T}} \in \mathbb{R}^{3}$

Table 1. Interaction design

\begin{tabular}{|c|c|c|}
\hline Index & $\begin{array}{c}\text { Perspective } \\
\text { of human }\end{array}$ & Speech of spherical robot \\
\hline 1 & $\begin{array}{c}\text { Listening to } \\
\text { direct speech }\end{array}$ & $\begin{array}{c}\text { Greeting the guest and } \\
\text { Providing information of } \\
\text { the university in soliloquy } \\
\text { or robot's conversation }\end{array}$ \\
\hline 2 & $\begin{array}{c}\text { Overlooking } \\
\text { indirect } \\
\text { interaction }\end{array}$ & $\begin{array}{c}\text { A spherical robot while } \\
\text { rolling at the front desk in } \\
\text { the faculty lobby }\end{array}$ \\
\hline
\end{tabular}

where $r$ is the radius of wheel and $L$ is the wheel base of robot.

Using these conditions above, the transition equations can be expressed as

$$
\begin{aligned}
& \dot{\boldsymbol{x}}=r \cdot v_{\omega} \cdot \cos \theta, \\
& \dot{\boldsymbol{y}}=r \cdot v_{\omega} \cdot \sin \theta, \\
& \dot{\boldsymbol{\theta}}=\frac{r}{L} \cdot v_{\psi},
\end{aligned}
$$

and $v_{\omega}$ and $v_{\psi}$ denote the translation vector and rotation vector as

$$
\begin{aligned}
& v_{\omega}=\frac{v_{r}+v_{l}}{2} \\
& v_{\psi}=v_{r}-v_{l} .
\end{aligned}
$$

where $v_{r}$ and $v_{l}$ denote the velocity of right wheel and left wheel during turning.

\section{Interaction design}

An interaction design is based on the proximate interaction and social interaction [17] that the human and robot are co-located. Based on the human-robot interaction, the proximate interaction with a mobile robot takes a form of a robot assistant, while the 
Table 2. Examples of speech design

\begin{tabular}{|c|c|c|}
\hline No. & $\begin{array}{l}\text { Question of } \\
\text { University-guest }\end{array}$ & $\begin{array}{l}\text { Answer of Spherical } \\
\text { Robot }\end{array}$ \\
\hline 1 & Where is this place? & $\begin{array}{l}\text { It is the Faculty of } \\
\text { Industrial Technology, } \\
\text { Suan Sunandha } \\
\text { Rajabhat University }\end{array}$ \\
\hline 2 & $\begin{array}{l}\text { Where is the Suan } \\
\text { Sunandha Rajabhat } \\
\text { University? }\end{array}$ & $\begin{array}{l}\text { Address: } 1 \text { U-thong } \\
\text { Nok Rd., Dusit, } \\
\text { Bangkok } 10300\end{array}$ \\
\hline 3 & $\begin{array}{l}\text { Where is the } \\
\text { Computer } \\
\text { Engineering } \\
\text { Department? }\end{array}$ & $\begin{array}{l}\text { Address: } 47 \text { Building, } \\
\text { Computer Engineering } \\
\text { Department, Faculty of } \\
\text { Industrial Technology }\end{array}$ \\
\hline 4 & $\begin{array}{l}\text { Where is the } \\
\text { Computer } \\
\text { Engineering } \\
\text { Laboratory? }\end{array}$ & $\begin{array}{l}\text { Address: } 6^{\text {th }} \text { Floor, } 47 \\
\text { Building, Computer } \\
\text { Engineering } \\
\text { Department, Faculty of } \\
\text { Industrial Technology }\end{array}$ \\
\hline 5 & $\begin{array}{l}\text { What is the head of } \\
\text { Computer } \\
\text { Engineering } \\
\text { Department's name? }\end{array}$ & $\begin{array}{l}\text { Dr. Sethakarn } \\
\text { Prongnuch }\end{array}$ \\
\hline 6 & $\begin{array}{l}\text { What is the Dr. } \\
\text { Sethakarn } \\
\text { Prongnuch's phone } \\
\text { number? }\end{array}$ & $+662-160-1440$ \\
\hline
\end{tabular}

human and robot interact as the companion.

An interaction design is shown in Table 1 with the examples of different speech prepared for the proposed spherical magnetic robot. Based on the perspective of a human, the interaction design consists of two interaction styles as listening to direct speech and overlooking indirect speech.

\subsection{Listening to direct speech}

According to the direct speech, this interaction style is greeting and facing to initiate communication in the human-robot interaction. The content of the speech is information about the university as shown in Table 2.

\subsection{Overlooking indirect interaction}

Overlooking in public spaces is an indirect interaction. A rolling robot with a ball shaped body and a domed head freely movement can attract the attention of people immediately for a first impression.

\section{Proposed CE-R1 algorithm}

The algorithm design is introduced in the software design of prototype CE-R1 spherical magnetic robot, which comprises three algorithms as a CE-R1 algorithm, a JoystickCE-R1 algorithm and a VoiceCE-R1 algorithm.
Algorithm 1. CE-R1 algorithm

1: INCLUDE ESP8266WiFi

2: INCLUDE Servo Motor

3: INCLUDE BylnkESP8266

4: DEFINE AUTH TOKENS

5: DEFINE SSID, URL, Port, Password

6: DEFINE DC Motor Pins [RMS, RMD1, RMD2, LMS, LMD1, LMD2]

7: DEFINE DC Motor Speed [G11, G12, G21, G22]

8: DEFINE DC Motor Speed [LG]

9: DEFINE JoystickCE-R1()

10: Blynk.begin(“AUTH TOKENS”, "SSID, URL, Port, Password")

11: DC Motor Speed $=$ Stop

12: FOR LOOP

13: Bylnk.run()

14: JoystickCE-R1()

15: END FOR LOOP

Algorithm 2. JoystickCE-R1 algorithm

1: INITIAL $\mathrm{X}, \mathrm{Y}$

2: INITIAL MinRange, MaxRange

3: DEFINE MoveControl()

4: MoveControl("X", "Y")\{

5: $\quad$ IF $(X \& \& \mathrm{Y}>=$ MinRange $) \& \& X<=$ MaxRange

6: $\quad$ OUTPUT RMS $=$ G11, RMD1 $=\mathrm{HIGH,}$ RMD2 $=$ LOW

7: $\quad$ OUTPUT LMS $=$ G12, LMD1 $=\mathrm{HIGH,}$ LMD2 $=$ LOW

8: $\quad$ ELSE IF $X>=$ MaxRange $\& \& Y>=$ MaxRange

9: $\quad$ OUTPUT RMS $=\mathrm{LG}, \mathrm{RMD} 1=\mathrm{HIGH}$, RMD2 = LOW

10: $\quad$ OUTPUT LMS $=$ G12, LMD1 $=\mathrm{HIGH,}$ $\mathrm{LMD} 2=\mathrm{LOW}$

11: $\quad$ ELSE IF $X>$ MaxRange \&\& $Y<=$ MaxRange

12: $\quad$ OUTPUT RMS $=\mathrm{G} 11, \mathrm{RMD} 1=\mathrm{HIGH}$, RMD2 = LOW

13: $\quad$ OUTPUT LMS $=$ Stop, LMD1 $=$ HIGH, LMD2 $=\mathrm{LOW}$

14: $\quad$ ELSE IF $X<=$ MinRange \& \& $\mathrm{Y}>=$ MaxRange

15: $\quad$ OUTPUT RMS $=$ G12, RMD1 $=\mathrm{HIGH,}$ RMD2 $=$ LOW

16: OUTPUT LMS $=\mathrm{LG}, \mathrm{LMD} 1=\mathrm{HIGH}$, LMD2 $=$ LOW

17: $\quad$ ELSE IF $X>$ MaxRange \& \& $\mathrm{Y}<=$ MaxRange

18: $\quad$ OUTPUT RMS $=$ Stop, RMD1 $=\mathrm{HIGH,}$ RMD2 $=$ LOW

19: $\quad$ OUTPUT LMS $=$ G12, LMD1 $=\mathrm{HIGH,}$ $\mathrm{LMD} 2=\mathrm{LOW}$

20: $\quad$ ELSE IF $Y>=$ MinRange $\& \& X>=$ MinRange $\& \& \mathrm{X}<=$ MaxRange

21: $\quad$ OUTPUT RMS $=$ G21, RMD1 $=$ LOW, $\mathrm{RMD} 2=\mathrm{HIGH}$

22: $\quad$ OUTPUT LMS $=\mathrm{G} 22, \mathrm{LMD} 1=\mathrm{LOW}$, $\mathrm{LMD} 2=\mathrm{HIGH}$

23: $\quad$ ELSE IF ( $X \& \& Y>$ MinRange) \&\& ( $\mathrm{X} \& \& \mathrm{Y}<$ MaxRange)

24: $\quad$ OUTPUT RMS = Stop

25: $\quad$ OUTPUT LMS = Stop

26: END IF \} 
Algorithm 3. VoiceCE-R1 algorithm

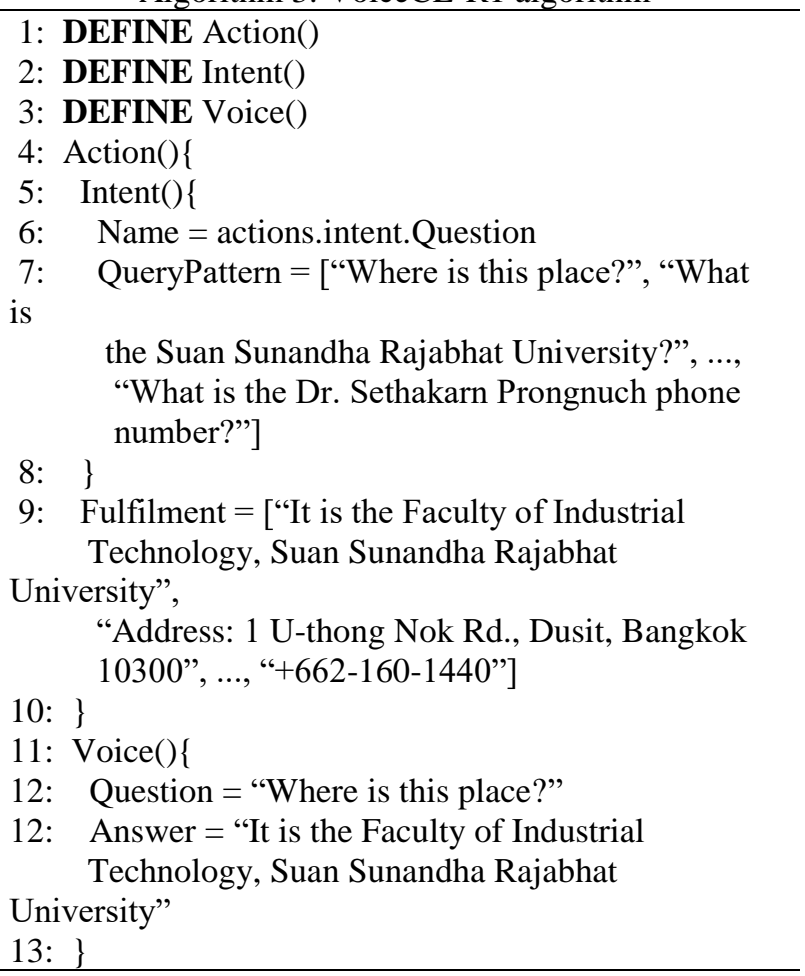

The main algorithm of prototype CE-R 1 is detailed in Algorithm 1 controlled by the ESP8266 NodeMCU board. Line 1-3 show the related libraries such as the standard library wireless LAN of ESP8266, the servo motor library, and the standard library of a Bylink application for connecting to the ESP8266. Line 4-8 describe all parameters for controlling the CE-R1 robot as an authentication token (AUTH TOKENS), a service set identifier (SSID), the uniform resource locator (URL), a network port (Port), a password for login (Password), DC motor pins that is the pin of right motor speed called "RMS", the pin of right motor driver 1 and 2 called "RMD1 and RMD2", the pin of left motor speed called "LMS", and the pin of left motor driver 1 and 2 called "LMD1 and LMD2", the 4-DC motor speed gears as G11, G12, G21, G22 and the DC motor speed low gear as LG. Line 9 shows the JoystickCE-R1 function. Line 10-11 present the initial parameter in the Bylink function and initial DC motor speed value. Line 12-15 show the loop process of controlling the spherical magnetic prototype robot.

For the JoystickCE-R1 algorithm, a joystick controller on display in the mobile application is applied for controlling the CE-R1 spherical magnetic robot introduced in Algorithm 2. Line 1-2 show the initial parameter for the motor drive parameter such as $\mathrm{X}, \mathrm{Y}$, the minimum speed of DC motor range is ' 0 ' (MinRange), and the maximum speed of DC motor range is ' 1023 ' (MaxRange). Line 3 shows the initial function of a robot movement controller

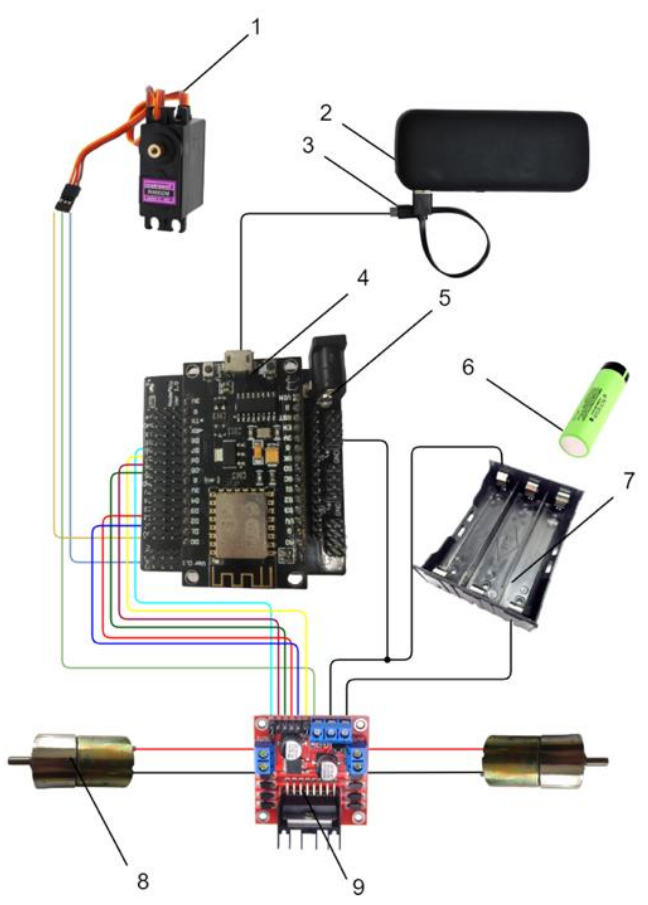

(a)

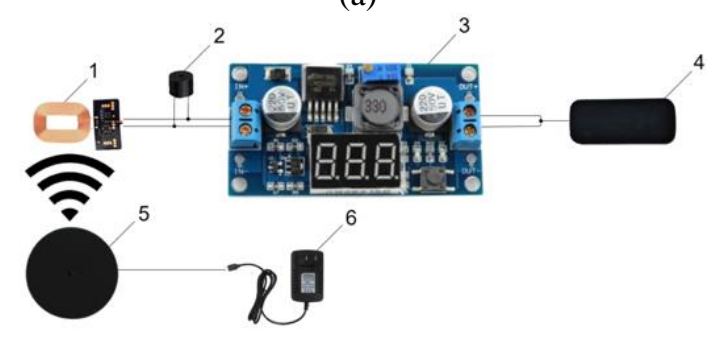

(b)

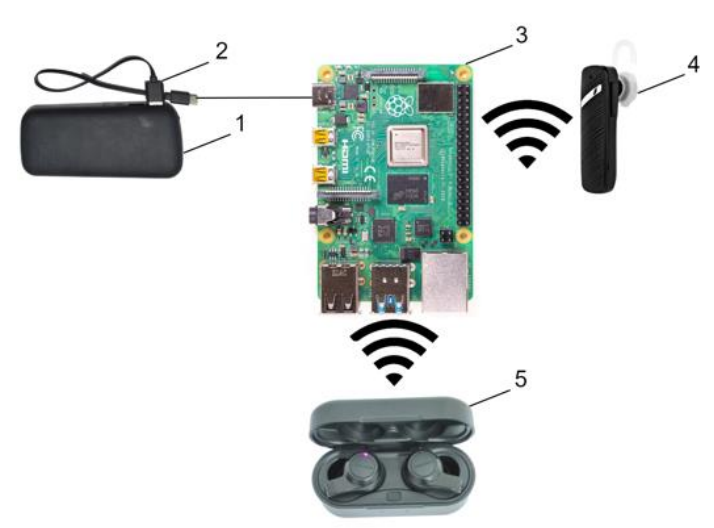

(c)

Figure. 4 Components of the spherical magnetic robot 'CE-R1': (a) board controller for controlling the head and body of robot (b) wireless charger and (c) voice recognition

(MoveControl). Line 4 shows the input value $\mathrm{X}$ and $\mathrm{Y}$ in the MoveControlfunction. Line 5-7 show the conditions for moving forward. Line 8-10 show the condition for turning right at 45 degrees. Line 11-13 show the condition for turning right. 
Table 3 The configuration of electrical characteristics of proposed CE-R1 robot system

\begin{tabular}{|c|c|c|c|}
\hline No. & Items & Input & Operating \\
\hline 1 & $\begin{array}{ll}\text { Servo } & \text { motor } \\
1.8 \mathrm{~kg} / \mathrm{cm} & \\
\end{array}$ & $6 \mathrm{~V}$ & $6 \mathrm{~V}$ \\
\hline 2 & $\begin{array}{l}\text { ESP8266 } \\
\text { NodeMCU board }\end{array}$ & $7-12 \mathrm{~V}$ & $3.3 \mathrm{~V}$ \\
\hline 3 & $\begin{array}{l}3 * \text { Lithium-ion } \\
\text { battery }\end{array}$ & $\begin{array}{l}3.7 \mathrm{~V} \\
2,040 \mathrm{mAh}\end{array}$ & \\
\hline 4 & DC motor 150rpm & $\begin{array}{l}12 \mathrm{~V} \text { (min. } \\
600 \mathrm{~mA})\end{array}$ & \\
\hline 5 & $\begin{array}{l}\text { L298N motor } \\
\text { drive module }\end{array}$ & $12 \mathrm{~V} 2 \mathrm{~A}$ & $5 \mathrm{~V}$ \\
\hline 6 & $\begin{array}{ll}\text { DC } & \text { wireless } \\
\text { charger } & \text { receiver } \\
\text { circuit board }\end{array}$ & $5 \mathrm{~V} 2 \mathrm{~A}$ & \\
\hline 7 & Passive buzzer & $5 \mathrm{~V}$ & $5 \mathrm{~V}$ \\
\hline 8 & $\begin{array}{l}\text { LM2596 DC-DC } \\
\text { Buck module }\end{array}$ & $\begin{array}{l}35 \mathrm{~V} \text { (max. } \\
3 \mathrm{~A})\end{array}$ & $5 \mathrm{~V}$ \\
\hline 9 & Power supply & $\begin{array}{l}5 \mathrm{~V} \quad 2.5 \mathrm{~A} \\
10,000 \mathrm{mAh}\end{array}$ & \\
\hline 10 & $\begin{array}{l}\text { 10W Xiaomi } \\
\text { wireless charger }\end{array}$ & $9 \mathrm{~V} 1.6 \mathrm{~A}$ & $9 \mathrm{~V} 10 \mathrm{~W}$ \\
\hline 11 & DC adaptor & $5 \mathrm{~V}$ & \\
\hline 12 & $\begin{array}{l}\text { Raspberry Pi } 3 \\
\text { Model B board }\end{array}$ & $\begin{array}{l}\text { 5V DC } \\
\text { USB-C } \\
\text { connector } \\
\text { (min. 3A) }\end{array}$ & \\
\hline 13 & $\begin{array}{l}\text { Akasaki Habibi } \\
\text { wireless Bluetooth }\end{array}$ & $5 \mathrm{~V}$ & \\
\hline 14 & $\begin{array}{l}\text { Jabees Firefly } \\
\text { wireless earbuds }\end{array}$ & $5 \mathrm{~V}$ & \\
\hline
\end{tabular}

Line 14-16 show the condition for turning left at 45 degrees. Line 17-19 show the condition for turning left. Line 20-22 show the condition for moving backward. Line 23-25 show the condition to stop the robot movement.

The proposed voice recognition algorithm of the CE-R1 robot shown in a VoiceCE-R1 algorithm is introduced in Algorithm 3. Line 1-3 show all initial functions including with 1) an action function is a wrapper combining between the intent and fulfillment as an answer to the question, 2) an intent function is specified for users' questions, and 3) a voice function of human-robot conversation comprises with the human's questions and robot's answers. Line 4-10 show the action function process for the query pattern of questions and answers. Line 11-13 show the voice function process.

\section{Design and kinematics}

\subsection{Configurations and features of prototype robot}

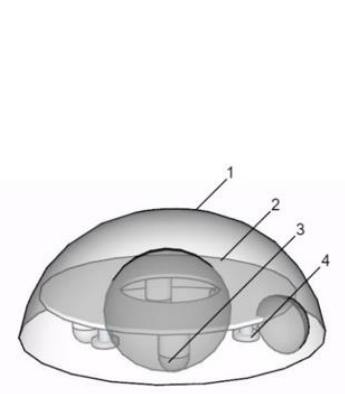

(a)

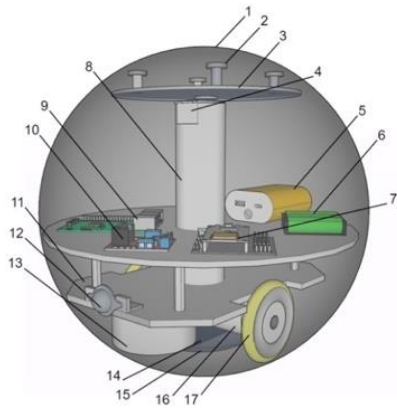

(b)

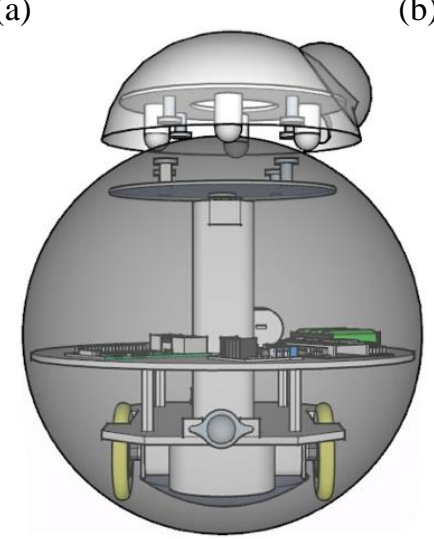

(c)
Figure. 5 Head and body of CE-R1 robot design: (a) head (b) body and (c) structure inside of CE-R1

This section describes the specification and features of the prototype CE-R1 spherical magnetic robot. The components of the CE-R1 spherical magnetic robot specification shown in Fig. 4 consist of the 3-main parts including a board controller for controlling the head and body of robot shown in Fig. 4 (a), the wireless charger system in Fig. 4 (b) and the voice recognition in Fig. 4(c), respectively.

Fig. 4 (a) shows the board Controller for controlling the head and body of robot. There are 9element inside of a body robot specification that are included with 1) a servo motor $1.8 \mathrm{~kg} / \mathrm{cm}$ of torque for rotating a head, 2) the $5 \mathrm{~V} 2.5 \mathrm{~A} 10,000 \mathrm{mAh}$ power supply, 3) a mini-USB cable, 4) the mini-USB port of ESP8266 NodeMCU board connected with a miniUSB cable, 5) the 2.5-inch jack of an additional power supply on a ESP8266 NodeMCU board, 6) the three of 2,040mAh Lithium-ion battery, 7) a battery tray, 8) the two of $12 \mathrm{~V}$ DC motor and 9) the L298N Motor drive module.

Fig. 4 (b) illustrates the wireless charger system. There are 6 elements of the wireless charger specification consist of 1) the $5 \mathrm{~V} 2 \mathrm{~A}$ DC wireless charger receiver circuit board, 2) the passive buzzer, 3) LM2596 DC-DC Buck module, 4) the 5V 2.5A $10,000 \mathrm{mAh}$ power supply, 5) the $10 \mathrm{~W}$ Xiaomi wireless charger and 6) 5V DC adaptor. 


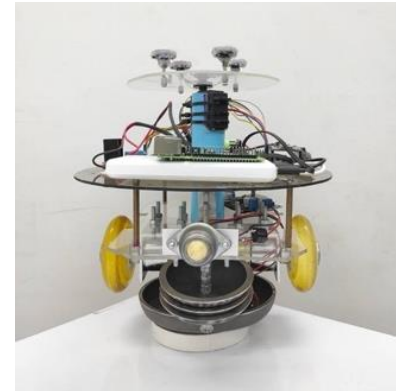

(a)

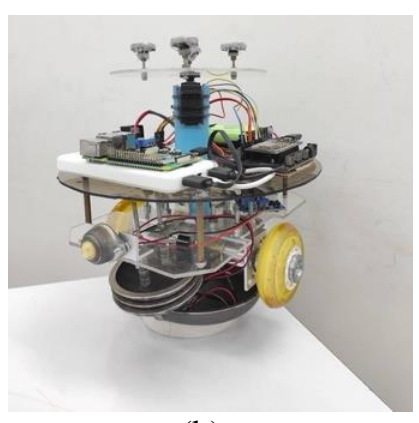

(b)
Figure. 6 A schematic view of proposed CE-R1spherical magnetic robot: (a) front view and (b) side view

Fig. 4 (c) shows the voice recognition specification, as 1) the $5 \mathrm{~V} 2.5 \mathrm{~A} 10,000 \mathrm{mAh}$ power supply, 2) a mini-USB connector, 3) the Raspberry Pi 3 Model B board, 4) Akasaki Habibi wireless Bluetooth and 5) the Jabees Firefly wireless earbuds.

The configuration and electrical characteristics of proposed CE-R1 robot system are detailed in Table 3.

\subsection{Structural Design of proposed CE-R1 spherical magnetic robot}

The structural design of the proposed spherical magnetic robot 'CE-R1' consists of two parts as: a domed head and a ball-shaped body shown in Fig. 5.

The head of CE-R1 robot shown in Fig. 5 (a) composes of four components as 1) a $9 \mathrm{~cm} \times 16.5 \mathrm{~cm}$ foam hollow domed head, 2) a $2 \mathrm{~mm}$ acrylic sheet 3 ) a set of $5 / 8$ ball transfer unit is the omnidirectional load-bearing spherical balls mounted at the base of the domed head for 360-degree transfer bearing, and 4) the four of a strong magnet for connecting with a ball shaped body.

A body of CE-R1 robot design shown in Fig. 5 (b) consists of 17 components as 1) a $32 \mathrm{~cm} \mathrm{x} 32 \mathrm{~cm}$ Plastic hollow sphere, 2) the four of a strong magnet for connecting with a domed head, 3 ) a $25 \mathrm{~cm}$ acrylic transparent circle disc, 4) the servo motor, 5) a power supply connecting with the Raspberry Pi board, 6) a Lithium-ion battery for the two of DC motor, the NodeMCU board, and a servo motor, 7) the NodeMCU board for processing and controlling motors, 8) 2-inch PVC stand, 9) the Raspberry Pi board for the voice recognition processing, 10) a motor driver module, 11) an acrylic circular sheet at the base of ball-shaped body, 12) a 50mm ball transfer unit, 13) 3-iron disc weight plates, 14) the circuit board of wireless charger receiver, 15) an iron circular base sheet, 16) the two motor for a body of robot movement and 17) the two rubber wheels for movement. Structure inside of CE-R1 is shown in Fig. 5 (c).
A schematic view of proposed CE-R1spherical magnetic robot is illustrated in Fig. 6.

\subsection{Kinematic model of proposed spherical magnetic robot}

Based on a non-holonomic constraint model of a differential drive above, we define the distance between the two wheels $L$ and the radius of the

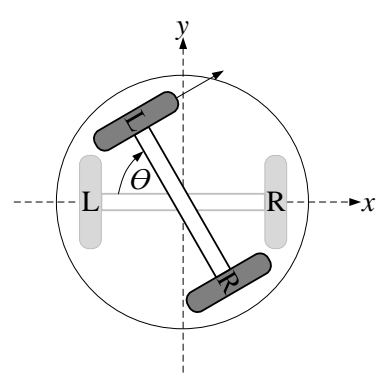

(a)

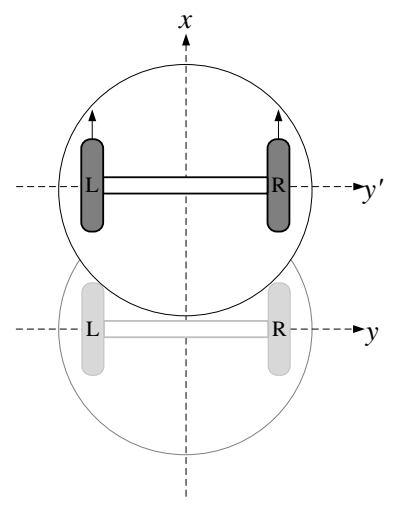

(c)

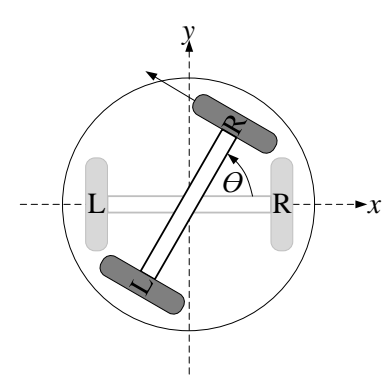

(b)

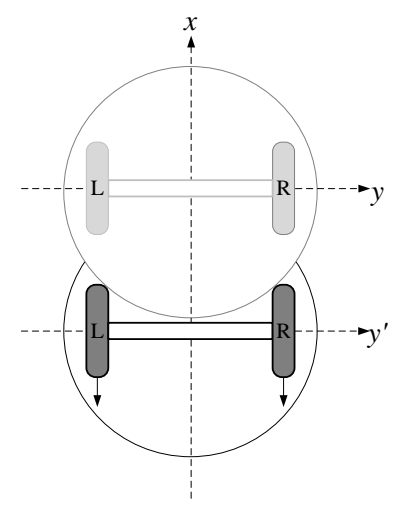

(d)
Figure. 7 Sphere movement of proposed spherical magnetic robot: (a) turn right (b) turn left (c) forward and (d) backward

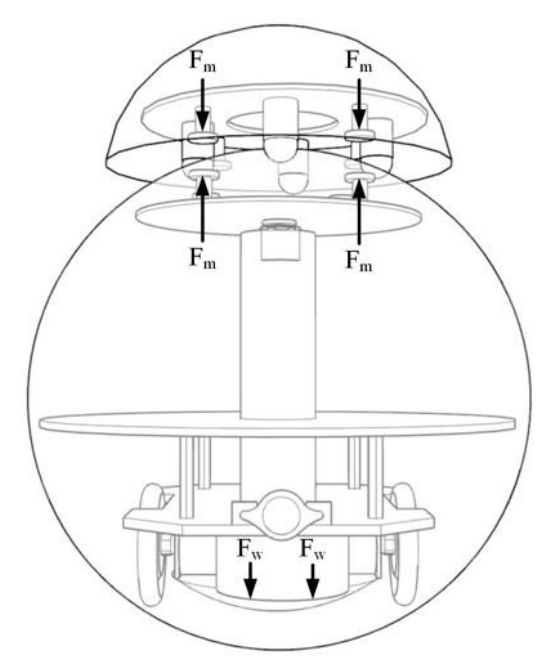

Figure. 8 Model illustration of magnetic balancing unit of CE-R1 
wheel $r$. Fig. 7 shows how the spherical magnetic robot moves the different actions as turning right, left, moving forward and backward, respectively.

For turning right, the right wheel is fixed and the left wheel rotates clockwise with $\theta$ angle. Then the spherical robot is turning in the right shown in Fig. 7 (a). Similarly, the right wheel rotate countercockwise at $\theta$ angle while fixing the left wheel shown in Fig. 7 (b). So, the spherical robot turns to the left. Hence, the spherical robot will move forward and backward in the direction that the wheels are pointing illustrated in Fig. 7 (c) and Fig. 7 (d).

Fig. 8 shows the MBU of the proposed spherical magnetic robot. There are 4 magnets at the base of head part and 4 magnets at the top of the IDU closed to the shell. It is seen that the magnetic forces $F_{m}$ between the head and body parts are forced to make the head part connected to the body part. The rollers are installed at the base of head part to make it smooth while rolling. The 3 -iron disc weight plates are added on the IDU, which is the weight force $F_{w}$ to make a balance.

\subsection{Application design}

The application design constitutes two parts shown in Fig. 9 as (a) start part and (b) controller part. The start part has two buttons consisting of a speech button for communication with a robot and a start button for controlling the CE-R1 robot. The controller part has three buttons comprising of a head controller called "HEAD" for rotating a domed head of CE-R1 robot. A joystick controller called "JOYSTICK" is used to control the 360-degree multi-directional for moving CE-R1. Then, the "OFF" button called "STOP" is used for terminating or emergency the CE-R1 robot.

A joystick button is used to control the CE-R1 movement through the application. There are four directions of joystick button as moving forwards and backwards, turning right and turning left relate to the four areas of joystick button. So, if the user pushes the top area of joystick button, the CE-R1 robot will move forwards. Then, if the user presses the bottom area, the CE-R1 will move backward. When the joystick button is pressed in the left area, the CE-R1 robot is turning left. Since, if the user pushes on the right-side of joystick button, the CE-R1 robot will be turning right.

\section{Tuning up and experimental results}

This section explains how to move the CE-R1 robot by setting the motor drive and tuning up the

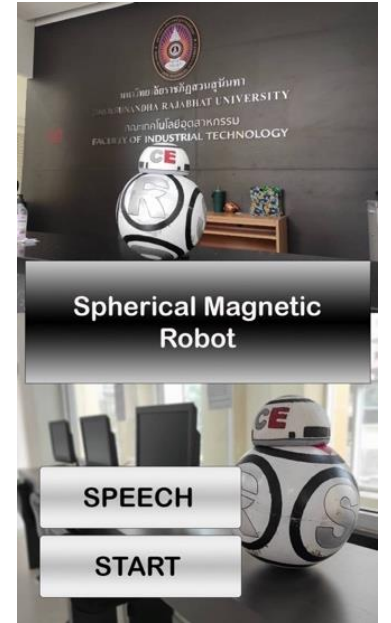

(a)

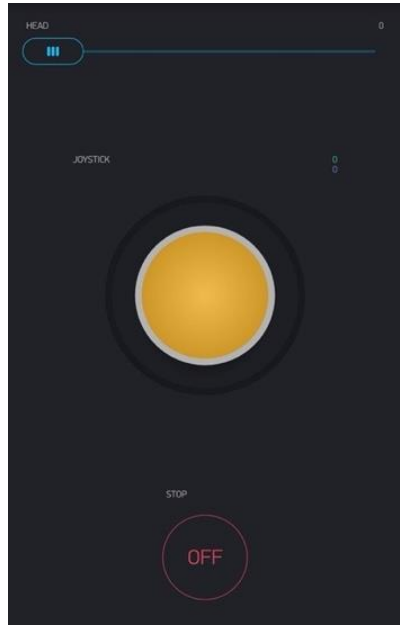

(b)
Figure. 9 Application design of CE-R1: (a) start part and (b) controller part

Table 4. A series of CE-R1 gears

\begin{tabular}{|c|c|c|}
\hline Index & $\begin{array}{c}\text { A type of CE-R1 } \\
\text { gears }\end{array}$ & $\begin{array}{c}\text { Output values } \\
\text { from 10-bit ADC } \\
\text { on ESP8266 } \\
\text { NodeMCU board }\end{array}$ \\
\hline 1 & Low Gear (LG) & $' 562-741 '$ \\
\hline 2 & Low Gear 1 (G11) & $' 742-791 '$ \\
\hline 3 & High Gear 1 (G12) & $' 792-811 '$ \\
\hline \hline 4 & Low Gear 2 (G21) & $' 812-861 '$ \\
\hline 5 & High Gear 2 (G22) & $' 862-1023 '$ \\
\hline
\end{tabular}

speed, which is interfacing a push bottom joystick with the ESP8266 NodeMCU board.

\subsection{Tuning up}

An analog joystick is used to transfer the human input into electrical signals. A joystick is using two potentiometers and a push bottom, where a potentiometer is positioned in the two-dimensional direction. The signal pin the joystick is read by the 10-bit Analog to Digital Converter (ADC) on the ESP8266 NodeMCU board, which the values for the joystick will range from ' $0-1023$ '.

The drive motor connected to each wheel controls the mechanism on the differential drive for moving forward or backward of CE-R1 movement. When the CE-R1 robot moves forwards, the signal pins on the right- and left-motor drive module are set to high. Similarly, if their signal pins are set to low, the CE-R1 robot will move by rolling backwards over the surface of a sphere.

Leading to the gear motors to adjust the speed of CE-R1 robot, there are a series of CE-R1 gears that can make up the kinematic chain concerning the output of the 10-bit ADC of ESP8266 NodeMCU board. The main purpose is to allow the increase from a low speed to a high speed without affecting the 
mechanism. A series of CE-R1 gears composes of 5 gears as shown in Table 4.

According to the motor drive calibration experiments, we found that the left wheel of CE-R1 robot has more friction than the right. Hence, a set of forward gears consist of the low gear (LG), the first low gear (G11) and the first high gear (G12), then a set of reverse gears comprises of the second low gear (G21) and the second high gear (G22), respectively.

By depending on the 10-bit ADC output, a standby mode is set at the output values between ' 0 561'. A set of forward gears are set to the output values starting between ' $562-811$ ', where the 10-bit ADC output values for the LG, G11 and G12 are about '562-741', '742-791' and '792-811'. A set of reverse gears are set to the output values between '812-1023', where the 10-bit ADC output values for the G21, G22 are ' $812-861$ ', '862-1023', respectively.

All a set of the 10-bit ADC output values to start a series of CE-R1 gears are from the experiments. Following [18], 10-bit ADC output from ESP8266 NodeMCU board will explain how to control the speed of the 12V DC motor connected to each CE-R1 wheel by using the pulse width modulation (PWM) signal.

PWM is applied to adjust the average voltage depending on the duty cycle that is the amount 'ON' and 'OFF' signal with a time period. A series of CE$\mathrm{R} 1$ gears is set starting from the joystick controller and then mapping the 10-bit ADC output from ' 0 1023' to a set of duty cycle of a PWM signal. Then, PWM signal is sent to drive actually the DC motor connected to each CE-R1 wheel. The drive motor related to a series of CE-R1 gears depending on the duty cycle of a PWM signal as illustrated in Fig. 10. According to moving forwards, a set of duty cycle of low gear (LG), low gear 1 (G11), high gear 1 (G12) is about $20 \%, 40 \%$ and $60 \%$, respectively. For moving backward, a set of duty cycle of low gear 2 (G21) and a high gear (G22) is about $80 \%$ and $95 \%$.

\subsection{Experimental results}

In this section, we describe the CE-R1 spherical robot movement at the top view in Fig. 11. The drive system of the CE-R1 robot is located inside a shell and will be able to transfer power to the outer shell for rolling. For the experiments, the CE-R1 robot is moving forward from the starting point to the target point as shown in Fig. 11 (a), which results in curved trajectory of the end after distance of one meter. Similarly, when the CE-R1 robot moves backward, the trajectory curve shows the results at the distance

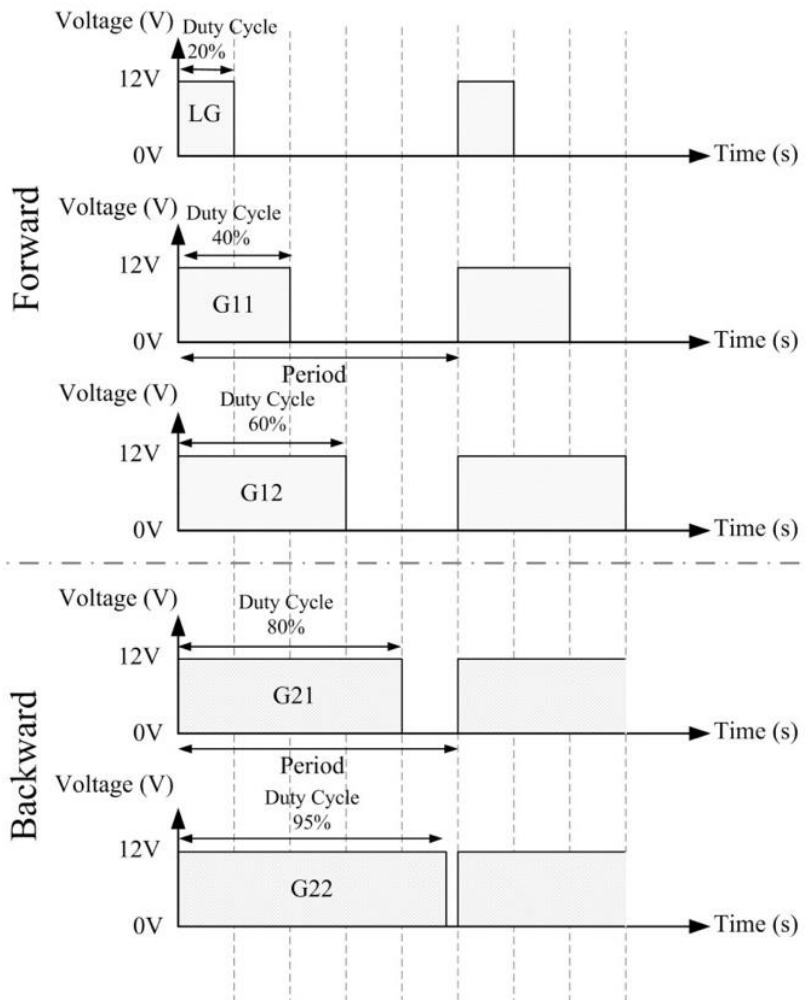

Figure. 10 Pulse width modulation for tuning up a series of CE-R1 gears

of one and a half meter in Fig. 11 (b). For turning left and right, the CE-R1 robot rolls to form a curve on the left and right side at 45 degrees after distance of one meter as shown in Fig. 11(c) and Fig. 11(d). Correspondingly, the CE-R1 robot turning left and right at 45 degrees moves a curve tothe left and right side at 65 degrees as illustrated in Fig. 11 (e) and Fig. 11 (f), respectively.

For the energy consumption, there are 5 random tests of proposed CE-R1 robot power supply with the different routes as shown in Fig. 12, which presents the voltage of power supply remaining at the half in 22 minutes. The average distance of proposed CE-R1 robot is around 170.3 meters at terminated. Wireless charger is fully charged within 420 minutes. Fig. 13 shows the DC current measured every 20 minutes while charging.

We conducted several experiments such as an analysis the CE-R1 movement controlling through application by the user in the university's lobby. The lobby is located on the 1st floor and near the front desk. Two elevators on the left side of the lobby are used as common entrances as shown in Fig. 14.

All the university-guests were supposed to pass through the elevator hall from the elevators to the front desk, during which they would encounter with the CE-R1 robot waiting for at the front desk as shown in Fig. 15. We consider that the human-robot 


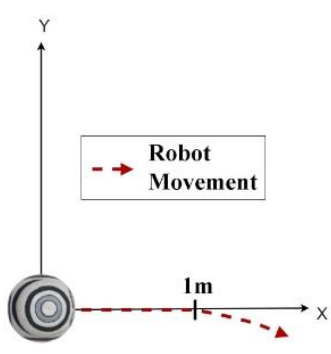

(a)

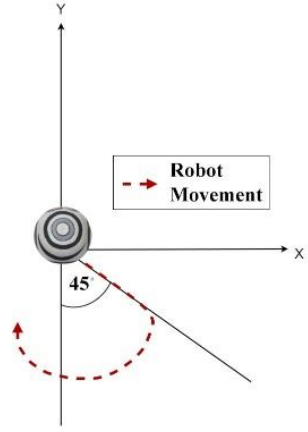

(d)

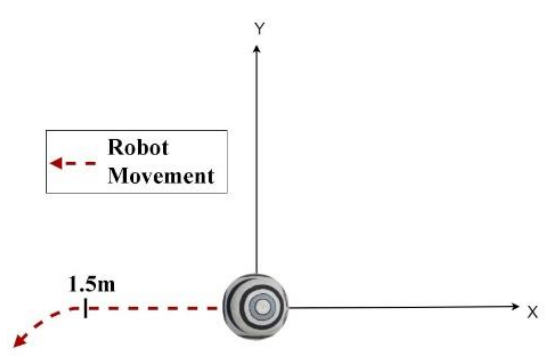

(b)

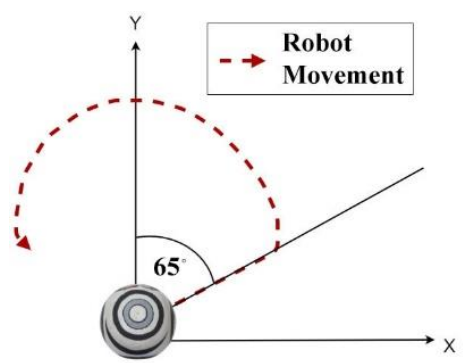

(e)

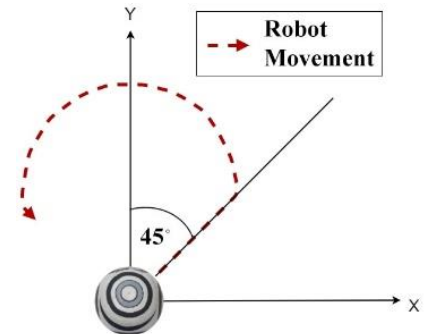

(c)

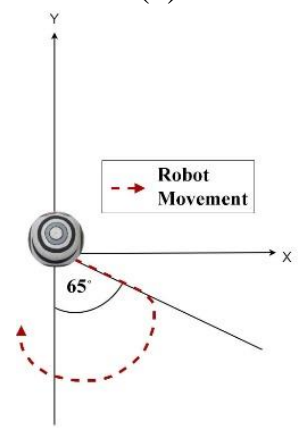

(f)

Figure. 11 Spherical magnetic robot CE-R1 movements at a top view: (a) forward (b) backward (c) turn left (d) turn right (e) turn left 65 degree and (f) turn right 65 degree

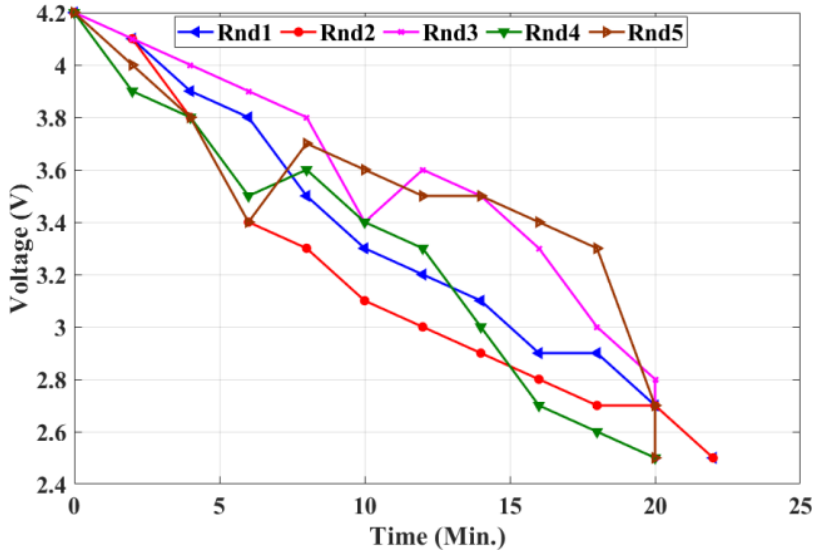

Figure. 12 Five random tests of CE-R1 robot power supply with the different routes

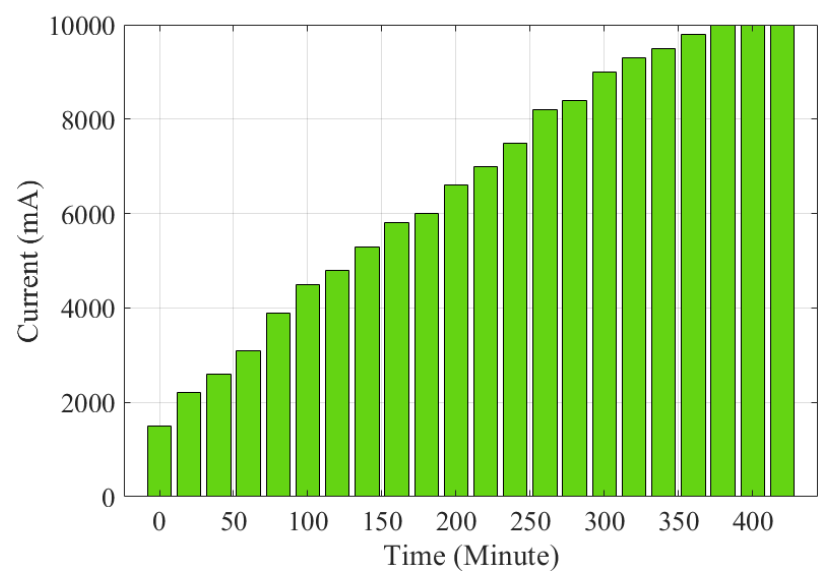

Figure. 13 DC current of wireless charger in $\mathrm{mA}$ versus time in minutes

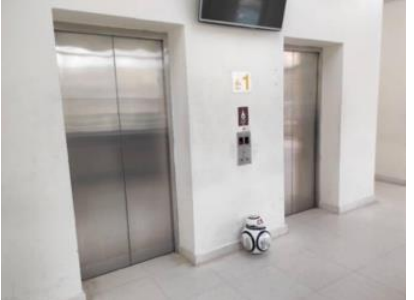

(a)

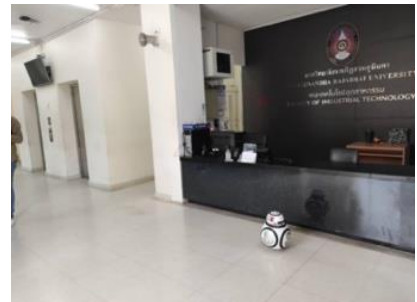

(b)
Figure. 14 CE-R1 movements around the faculty hall: (a) elevator hall and (b) lobby hall

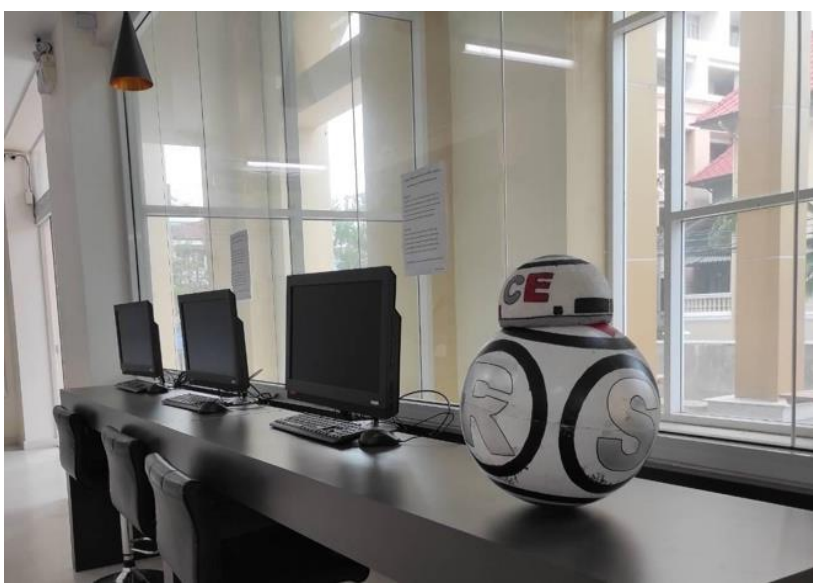

Figure. 15 Spherical magnetic robot CE-R1 at the lobby hall of faculty

practical interaction (HRI) will be related to the CE$\mathrm{R} 1$ robot's movement. There are some experiments of the robot as a faculty assistant robot accompanying with the guest. During providing the information of the faculty and department, the CE-R1 will turn 
its domed head to face the faculty, guest while starting the conversations through Bluetooth shown in Fig. 16. The CE-R1 will work as a guide rolling with the guest around the faculty area as shown in Fig. 17.

\section{Conclusion and future developments}

In this work, we have introduced the CE-R1 spherical magnetic robot rolled by an inner drive unit (IDU) and a magnetic balancing unit (MBU). There are two parts of a CE-R1 robot as a domed head and a ball-shaped body with contactless and controlled through the application. A non-holonomic model and wheel-drive locomotion have been proposed by a differential drive from the inner drive unit inside the sphere. The contactless of a domed head and a ballshaped body of CE-R1 is applied by using the magnetic force in the MBU. A differential drive of 'CE-R1' is derived and deployed in the IDU using the multi-single computer board controller. The hardware design consists of the multi-single board computer for wireless charger, voice recognition system and controlling.

The experiments are tested in practice as a dynamic analysis and a faculty-assistive guide robot to provide the information controlled through application at the faculty lobby area in the Suan Sunandha Rajabhat University. The voltage of power supply remaining at the half is in 22 minutes. The average distance of proposed CE-R1 robot is around 170.3 meters, while moving until terminated.

Our research will help to understand the practical effectiveness of movement in a public space in order to inspire the faculty-assistive robot design.

\section{Conflicts of Interest}

The authors declare no conflict of interest.

\section{Author Contributions}

Conceptualization, Sethakarn Prongnuch and Suchada Sitjongsataporn; methodology, Sethakarn Prongnuch; software and hardware, Sethakarn Prongnuch; validation, Sethakarn Prongnuch and Suchada Sitjongsataporn; writing - original draft preparation, Sethakarn Prongnuch; writing - review and editing, Sethakarn Prongnuch; visualization, Suchada Sitjongsataporn; supervision, Suchada Sitjongsataporn.

\section{Acknowledgments}

We would like to thank Warawut Suriwong, Marutthapol Chantharasri, Sakkarin Pengjeam, and

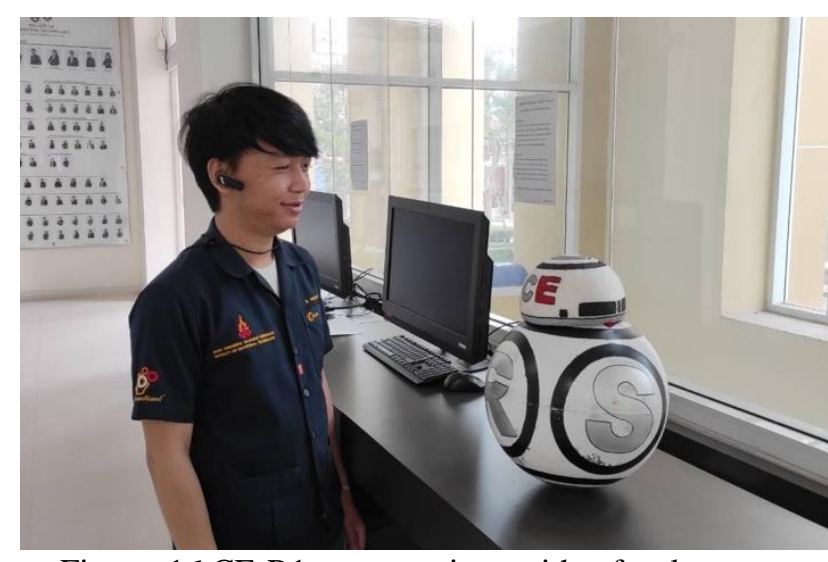

Figure. 16 CE-R1 conversations with a faculty guest through Bluetooth

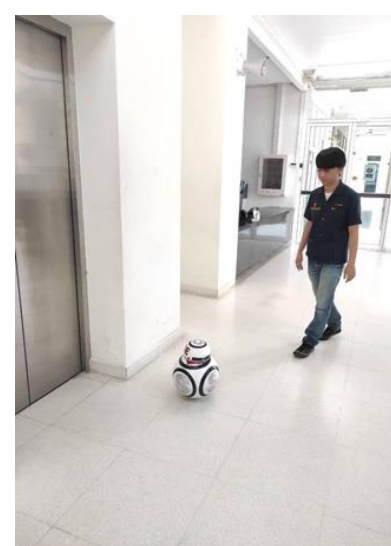

(a)

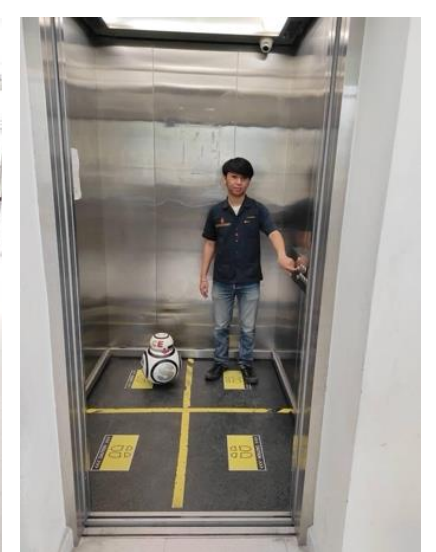

(b)
Figure. 17 Experiments for CE-R1 movement in the faculty: (a) rolling the direction to an elevator and

(b) standing inside an elevator

Kwanruan Rusmee at Department of Computer Engineering, and Aphirak Thitinaruemit at Department of Electrical Technology, Faculty of Industrial Technology, Suan Sunandha Rajabhat University in Bangkok, Thailand.

\section{References}

[1] C. Sánchez and E. Gelardo, "How does BB-8 work?", Available: https://howbb8works.com/ [Accessed Feb. 22, 2021].

[2] Lucasfilm Ltd, "Star Wars: Episode VII The Force Awakens News", Available: https://www.starwars.com/news/category/theforce-awakens [Accessed Feb. 22, 2021].

[3] Y. Pan, H. Okada, T. Uchiyama, and K. Suzuki, "On the Reaction to Robot's Speech in a Hotel Public Space", International Journal of Social Robotics, Vol. 7, No. 5, pp. 911-920, 2015.

[4] F. Rubio, F. Valero, and C. Llopis-Albert, "A Review of Mobile Robots: Concepts, Methods, Theoretical Framework, and Applications", 
International Journal of Advanced Robotic Systems, Vol. 16, No. 2, pp. 1-22, 2019.

[5] M. Fuad, T. Agustinah, and D. Purwanto, "Collision Avoidance of Multi Modal Moving Objects for Mobile Robot Using Hybrid Velocity Obstacles", International Journal of Intelligent Engineering and Systems, Vol. 13, No. 3, pp. 407-421, 2020.

[6] A. V. Borisov, A. A. Kilin, and I. S. Mamaev, "Dynamics and Control of an Omniwheel Vehicle", Regular and Chaotic Dynamics, Vol. 20, No. 2, pp. 153-172, 2015.

[7] Y. L. Karavaev1 and A. A. Kilin, "The Dynamics and Control of a Spherical Robot with an Internal Omniwheel Platform", Regular and Chaotic Dynamics, Vol. 20, No. 2, pp. 134152, 2015.

[8] R. Chase and A. Pandya, "A Review of Active Mechanical Driving Principles of Spherical Robots", Robotics, Vol. 1, No. 1, pp. 3-23, 2012.

[9] W. Lerdsithisuth, P. Kiattipatarachai, S. Prongnuch, and N. Narongrat, "Robotic Promoter Design for Faculty of Industrial Technology, SSRU (In Thai)", In: Proceedings of National Conference on Local \& Global Sustainability, Bangkok, Thailand, pp. 12421255, 2018.

[10] C. Marutthapol, S. Warawut, P. Sakkarin, S. Prongnuch, and K. Rusmee, "The Development of Suan Sunandha Rajabhat University PR Robot (In Thai)", In: Proceedings of Engineering, Science, Technology and Architecture Conference, Nakhon Ratchasima, Thailand, pp. 881-886, 2020.

[11] A. Halme, T. Schönberg, and Y. Wang, "Motion Control of a Spherical Mobile Robot", In: Proceedings of the IEEE International Workshop on Advanced Motion Control, Mie, Japan, pp. 259-264, 1996.

[12] V. A. Joshi and R. N. Banavar, "Motion Analysis of a Spherical Mobile Robot", Robotica, Vol. 27, No. 3, pp. 343-353, 2009.

[13] Z. Minghuia, Z. Qianga, L. Jinkunb, and C. Yaoa, "Control of a Spherical Robot: Path Following Based on Nonholonomic Kinematics and Dynamics", Chinese Journal of Aeronautics, Vol. 24, No. 3, pp. 337-345, 2011.

[14] J. Chen, P. Ye, H. Sun, and Q. Jia. "Design and Motion Control of a Spherical Robot with Control Moment Gyroscope", In: Proceedings of the IEEE International Conference on Systems and Informatics, Shanghai, China, pp. 114-120, 2016.
[15] L. Smoot and D. Ruiken, "Magnetic Spherical Balancing Robot Drive", United States Patent 390413, Sep. 2, 2012.

[16] A. Pepe, "Introduction to Mobile Robotics", Available: https://core.ac.uk/download/pdf/31082555.pdf [Accessed Feb. 22, 2021].

[17] T. Kanda, "Human-Robot Interaction", Available: https://humanrobotinteraction.org/1introduction/ [Accessed Feb. 22, 2021].

[18] D. Nedelkovaski, "Arduino DC Motor Control Tutorial-L298N|PWM|H-Bridge", Available: https://howtomechatronics.com/ tutorials/arduino/arduino-dc-motor-controltutorial-1298n-pwm-h-bridge/ [Accessed Feb. 27, 2021]. 